\title{
Methodology for assessing the environmental characteristics of various methods of generating electricity
}

\author{
Ekaterina Gryznova ${ }^{1, *}$, Vadim Davydov ${ }^{1,2}$, Yuri Batov ${ }^{1}$, Valentin Dudkin ${ }^{3}$ Danila Puz'ko ${ }^{1}$, Nikita Myazin ${ }^{1}$ and Vasiliy \\ Rud $^{2}$ \\ ${ }^{1}$ Higher School of applied physics and space technologies, Peter the Great Saint Petersburg Polytechnic University, Saint Petersburg, \\ 195251, Russia \\ ${ }^{2}$ All Russian Research Institute of Phytopathology, Moscow Region 143050, Russia \\ ${ }^{3}$ The Bonch-Bruevich Saint Petersburg State University of Telecommunications, Saint Petersburg 193232, Russia
}

\begin{abstract}
The article considers the energy efficiency of energy production from various types of fuel. The analysis of the negative impact of the use of various types of fuel on the environment. The most significant indicators for assessing the environmental efficiency of the use of fuel for electricity production are established. A comparison is made with the performance indicators that are currently used. The advantages and disadvantages are established. The necessity of developing a more effective methodology for assessing environmental performance is substantiated. A new methodology for assessing the environmental efficiency of using various methods for the production of electricity is proposed. Research results are presented.
\end{abstract}

\section{Introduction}

In recent years, there has been a significant increase in the consumption of primary energy and electricity [1-9]. Currently, the most demanded for energy production are oil, coal, gas and uranium [3, 4, 5, 10-15]. In the coming decades, they will remain the main sources of energy $30,23,24,12 \%$, respectively. However, the limited availability of oil and gas is obvious. Their active use is visible only for several decades. During this time, a replacement should be prepared for these sources of raw materials $[4,5,6,16-19]$. Therefore, it is necessary to develop new technologies that allow the use of renewable energy sources. One of them is solar energy [19-28].

The annual flow of solar energy to the Earth is five times more than all the energy that comes from fuel energy sources. Still there is wind and geothermal energy. Hydropower has now almost completely mastered all its possible resources [29-31]. The exception is small hydropower plants, which are now being actively revived. But they can no longer make a significant contribution to the total amount of energy produced.

Most renewable energy sources, except hydropower, are low potential systems. This means that the large energy capacities necessary for the functioning of modern industries cannot be obtained with their help. They are auxiliary in nature, even with a share of electricity generated up to $15 \%$ (for example, Israel or Spain).
Studies in the field of world energy and possible ways of its development indicate that in the near future the possible role of renewable energy sources in a number of countries will change [17-22, 32, 33]. They will go beyond the limits of auxiliary energy, which solves local problems. In addition, new types of energy give rise to new types of environmental consequences that can lead to changes in environmental conditions, including regionally and globally.

An important impact factor is the quantitative indicator of resource consumption. Depletion of resources is becoming increasingly relevant, and access to resources is an increasing factor in world development and a major factor in sustainable development. Attempts to overcome the emerging environmental crisis are reflected in the UN global program, called the sustainable development program. The transition to sustainable development means a balanced solution to the problems of socio-economic development, meeting the needs of the present and future generations while limiting the impact on the biosphere to an environmentally acceptable limit determined by the adaptive capabilities of the biosphere [34-38]. Under these conditions, environmentally more acceptable sources of energy are the basis for such a development [39-45].

\section{Methods}

The main problem of modern energy, and all human activity is, the ecological system of the Earth can not cope with the growing load on it (emissions of harmful substances). From this big problem many whiter ones

Corresponding author: katya.gryaznova@mail.ru 
appear. A solution that is getting harder every year. This is due to the fact that there is a conflict of interests of human life. On the one hand, it is necessary to increase electricity production. On the other hand, to preserve the environment, the state is monitored continuously [6, 7 , $24,25,27,28,45]$. To do this, it is necessary to determine the promising areas of energy development, which will solve these problems at the same time. The technique developed by us will allow us to more correctly solve this problem.

Consider the main characteristics of different methods of generating electricity in two ways: greenhouse gas emissions and energy release per unit mass. The results of this analysis are presented in table 1 .

Table 1. Efficiency of various methods for generating electricity.

\begin{tabular}{|l|c|c|}
\hline \multicolumn{1}{|c|}{ Mode of production } & $\mathbf{C O}_{2}$ emissions & $\begin{array}{c}\text { The amount of energy per 1 } \\
\mathbf{k g} \text { of substance, } \mathbf{k W} \cdot \mathbf{h}\end{array}$ \\
\hline Combustion: & 2.76 from burning $1 \mathrm{t}$ & 7 \\
\hline Coal & 2.04 from burning $1 \mathrm{t}$ & 11 \\
fuel oil & 1.62 from burning $1 \mathrm{t}$ & 14 \\
natural gas & 0 & $24 \cdot 10^{6}$ \\
& 0 & $60 \cdot 10^{6}$ \\
$6940 \cdot 10^{12}$ \\
Atomic Energy \\
Thermonuclear energy \\
Quark-gluon level
\end{tabular}

Analysis of the data presented shows the high efficiency of atomic and thermonuclear energy. This is logical, since the energy in the solar system exists thanks to two "reactors": nuclear inside the Earth and thermonuclear on the Sun.

A complete solution to the problem of providing all with energy could be mastering the energy of fusion. However, studies of recent years have shown that at the current level of development of engineering and technology on the way to the full use of thermonuclear energy there are technical problems that have been solved for the past 50 years without significant success. Therefore, it is premature to count on certain plans related to thermonuclear fusion.

Thus, among the replacement options, only modern technologies of coal, gas, fuel, solar and nuclear energy will allow realizing to cover the growing energy needs of mankind for the next several hundred years. When comparing their environmental characteristics, the latter two are preferred. In a number of countries, the energy sectors associated with the use of wind and biomass are successfully developing. The use of these types of energy production has its pros and cons for the ecology and wildlife of the planet. Their characteristics of the environmental efficiency of energy production are different from those of other types of fuel. It should also be noted that when using each type for energy, it is necessary to consider various factors, including climatic ones. This was previously not taken into account in the works of many authors $[6,7,15-18,46]$.

We present very brief characteristics of the main sources of electricity production:

1. Coal. Emissions from coal stations have caused acid rain, which destroys vegetation, soil, water bodies and affects people's health. One thermal power plant with a capacity of $1000 \mathrm{MW}$, operating on coal with a sulfur content of about $3.5 \%$, despite cleaning agents, emits about 140 thousand tons of sulfur dioxide per year into the atmosphere, from which about 280 thousand tons of sulfuric acid is formed. Wind raises black smog from the surface of ash dumps, forming dust storms. The annual volume of slag waste (ash) of thermal power plants in Russia exceeds 100 million tons. In addition, in the process of burning coal, radioactive pollution of the environment occurs, the radionuclides contained in it $\left({ }^{238} \mathrm{U},{ }^{210} \mathrm{~Pb},{ }^{40} \mathrm{~K},{ }^{210} \mathrm{Po},{ }^{226} \mathrm{Ra},{ }^{228} \mathrm{Ra}\right.$, ${ }^{230} \mathrm{Th}$ and etc.) are released into the atmosphere and concentrated in ash, the release of radioactive substances per unit of energy received at coal TPPs is greater than at nuclear power plants.

2. Gas. The cleanest fuel for thermal power plants is natural gas. In some cases, shale gas is added to it, which is produced commercially in the United States. Unfortunately, its extraction poses great environmental problems: pollution of aquifers with highly toxic substances and surface water bodies with wastewater, methane emissions into the atmosphere, increased radioactive background in production areas, increased likelihood of earthquakes, and the removal of significant land and water resources from circulation.

3. Oil. The main environmental problems arising from the extraction and use of oil as an energy source are associated with chemical pollution of groundwater during production, chemical and thermal pollution of surface water, the formation of an oil film, disturbance of the habitats of the fauna and the growth of flora, pollution and degradation of soil cover, significant water intake.

4. Oil has another major drawback - a negative impact on the sustainable development of mankind. Replacing oil with a more efficient source of energy is the main task of specialists around the 
world. This is not implemented at the moment, which leads to conflicts.

5. Hydropower. Of all types of renewable energy sources, only hydropower currently makes a significant contribution to global electricity production (less than 7\%). In most industrialized countries, the hydropower potential insignificant in volume remains unused, which is primarily due to the need to alienate significant territories during the organization of hydropower plants. The main environmental consequences of using hydropower are as follows: flooding of agricultural land and human settlements; violation of the water balance, which leads to a change in the conditions of existence of flora and fauna; climatic consequences (change in heat balance, increase in precipitation, wind speed, cloud cover, etc.); siltation of a reservoir and coastal erosion, deterioration of selfpurification of running water and a decrease in oxygen content, impairment of free movement of fish; danger of major accidents.

6. Nuclear power. In addition to the fact that nuclear power plants do not consume oxygen, do not emit harmful chemicals into the atmosphere and water bodies, they significantly save the consumption of fossil fuels, whose reserves are quite limited. In the most developed countries of the world (France, Japan, the USA, China, and Russia), nuclear energy can save up to 440 million tons of coal per year (65.3 million tons in our country), 350 million tons of oil (40.3 million tons), up to 280 billion $\mathrm{m}^{3}$ of gas $\left(36.8\right.$ billion $\left.\mathrm{m}^{3}\right)$, prevent the burning of over 450 million tons of oxygen (36 million tons), preserve land on the territory of 70 thousand ha (11 thousand ha). The problems of spent fuel storage and the ever-increasing costs of ensuring the safety of nuclear power plants.

7. Solar power. Solar power plants are effective only for areas with a high level of insolation. In the middle zone of the European part of the Russian Federation, the annual average solar radiation intensity is $150 \mathrm{~W} / \mathrm{m}^{2}$, which is 10000 times less than the heat fluxes in the boilers of thermal power plants. The expediency of its use is justified when the difference is no more than 10 times. When using solar energy, environmental problems arise: the alienation of large land areas, their possible degradation - only for a solar power plant with an electric capacity of $1 \mathrm{GW}$ in the southern strip of the European part of the Russian Federation at efficiency $15 \%$ requires a minimum area of $47 \mathrm{~km}^{2}$; pollution of territories with hazardous substances during incomplete utilization of spent solar panels; change in heat balance, humidity, wind direction in the area. station location.

8. Wind power. This energy industry is developing rapidly in a number of countries, despite its negative impact on the environment: alienation of large land areas (stations are carried out to sea); unregulated source of energy (calm sea); noise impacts, with a plant power of 2-3 MW, it becomes necessary to turn them off at night; interference with bird migration paths (a plant with a capacity of 2-3 MW should have a wind wheel diameter of 100 $\mathrm{m})$; local climatic changes due to disruption of the natural circulation of air flows; adverse effects on marine animals when placing wind turbines in the aquatic environment; landscape incompatibility, unattractiveness, visual discomfort.

9. Energy geothermal, tidal and biomass. This type of energy has a lot of disadvantages and a number of advantages. The most widely used is geothermal energy. It is very effective for individual complexes with a low level of energy consumption. In other cases, the economic and environmental efficiency of its use is low. The remaining two types of energy are used locally and almost do not contribute to the global energy system. In some cases, their use improves the ecological condition of the territory.

An analysis of all the factors presented shows that it is necessary to develop an adequate system for assessing the environmental efficiency of electricity production using different types of energy resources. It is proposed to use coefficients in relative units. When considering, first of all, the following factors should be taken into account: the amount of greenhouse gases and harmful substances emitted into the atmosphere, the amount of discharges into water sources, waste generation, land disposal, radioactivity for the environment and risk to people. The most harmful effect is 1 . A value of $\mathrm{K}=0$ means no impact. In table 2 presents the result of our analysis.

Table 2. Environmental performance indicators for different methods of energy production.

\begin{tabular}{|l|c|c|c|c|c|c|}
\hline \multicolumn{1}{|c|}{ Indicator } & Coal & Gas, oil & Hydropower & The sun & Wind & Atomic Energy \\
\hline The amount of greenhouse gases emitted & 1.0 & 0.72 & 0.01 & 0.07 & 0.03 & 0.01 \\
Emission of harmful substances into the atmosphere & 1.0 & 0.43 & 0.01 & 0.5 & 0.01 & 0.01 \\
Discharge of harmful substances into water sources & 0.5 & 0.04 & 0.01 & 0.01 & 0.01 & 0.01 \\
Waste generation & 1.0 & 0.17 & 0.01 & 0.3 & 0.3 & 0.01 \\
Alienation of land resources & 0.01 & 0.01 & 1.0 & 0.33 & 0.55 & 0.01 \\
Release of radioactive substances into the environment & 0.5 & 0.04 & 0.01 & 0.01 & 0.01 & 0.5 \\
Risk to people & 1.0 & 0.03 & 0.09 & 0.29 & 0.02 & 0.05 \\
\hline
\end{tabular}

In fig. 1 for a more illustrative example presents the dependence of various environmental efficiency coefficients $\mathrm{K}$ of different methods of energy production. 

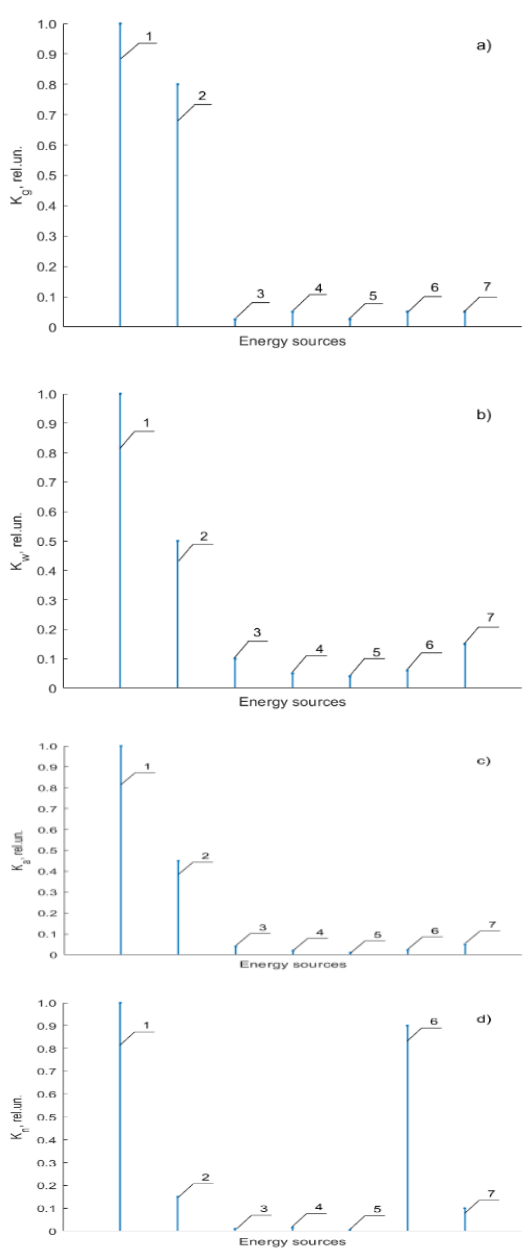

Fig. 1. Comparative indicators of the coefficients of environmental efficiency of different methods of energy production. Graphs: a) corresponds to the coefficient $\mathrm{K}_{\mathrm{g}}$, which takes into account the amount of greenhouse gases emitted, b) the coefficient $\mathrm{K}_{\mathrm{w}}$ - the discharge of harmful substances into water bodies, $c$ ) - the coefficient $\mathrm{K}_{\mathrm{a}}$ - the emissions of harmful substances into the atmosphere, d) - the coefficient $K_{n}$, - the amount emitted in atmosphere of radioactive substances.

Analysis of the results presented in fig. 1 and table 2 shows that solar, hydro and wind energy have high environmental efficiency. Nuclear energy is located close to them. This confirms the calculation of the complex indicator $\mathrm{K}$ of negative impacts on the environment and humans. In fig. 2 shows an example of calculating K using our methodology.

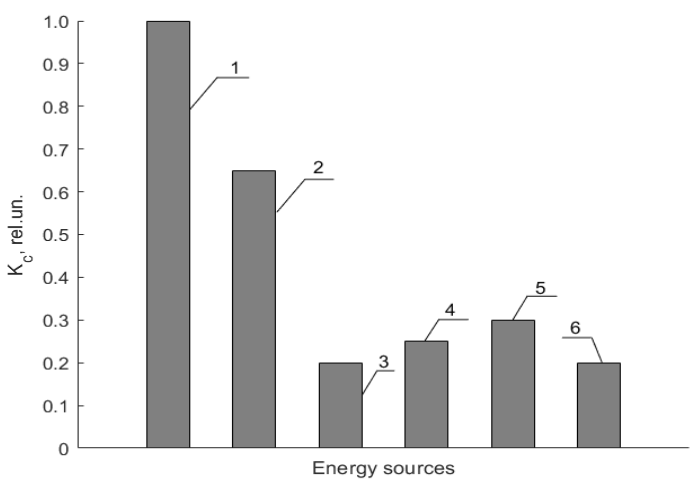

Fig 2. Comparative indicators of the complex coefficient $\mathrm{K}_{\mathrm{c}}$ of environmental efficiency for various methods of energy production.

The result obtained in fig. 2 , as well as taking into account a number of factors discussed above (the total generated power of electric energy, etc.), we can conclude that the most promising for the development of mankind are solar and nuclear energy.

\section{Conclusion}

The results obtained allow us to draw the following conclusions. The situation in the world shows that oil remains the dominant energy carrier, providing more than $1 / 3$ of the total needs, and especially the transport sector, although its production increased at a low rate (less than $1 \%$ per year). In the last decade, the complexity of technological efforts and financial costs for oil production has been growing. Moreover, oil has become a destabilizing factor in the sustainable development of both the economy and the political system.

The influence of global environmental problems (climate change, depletion of resources, waste, clean air and the oceans) on the energy production process is increasing. In addition, every year more and more energy is needed to solve them. This, as well as depletion of fuel reserves, leads to disaster. All calculations and studies, as well as the experience in operating power plants, show that the main emphasis in the development of energy in our time must be placed on the solar and nuclear. This will allow humanity to solve a number of very painful issues and will give time to bring the technology of thermonuclear production of electric energy to industrial production.

\section{References}

1. N.D. Agafonova, M.Y. Egorov, V.V. Sergeev, M.A. Gotovskii, P.A. Kruglikov, M.E. Lebedev, A.V. Sudakov, E.D. Fedorovich, B.S. Fokin, Atomic Energy, 123(3), 154-158 (2018)

2. J. Kaikko, A. Mankonen, E. Vakkilainen, V. Sergeev, Energy Procedia, 120, 572-579 (2017)

3. M. Petrichenko, V. Sergeev, E. Kotov, D. Nemova, D. Tarasova, Advances in Intelligent Systems and Computing, 983, 839-848 (2019)

4. A.L. Sirotkina, E.D. Fedorovich, V.V. Sergeev, High Temperature, 56(5), $732-737$ (2018)

5. T.J.B. Taweel, E. Sokolova, V. Sergeev, D.B. Solovev, IOP Conference Series: Materials Science and Engineering, 463(1), 032101 (2018)

6. O.V. Novikova, A.N. Grishkin, I.S. Khrebetenko, N.A. Yudina, IOP Conference Series: Earth and Environmental Science, 288(1) 012065 (2019)

7. T. Bugaeva, A. Khabarov, O. Novikova, U. Plotkina, IOP Conference Series: Materials Science and Engineering, 497(1), 012056 (2019) 
8. V.V. Davydov, Russian Physics Journal, 42(9), 822825 (1999)

9. V.V. Davydov, V.I. Dudkin, A.Yu. Karseev, Russian Physics Journal, 58(2), 146-152 (2015)

10. R.S. Kashaev, E.G. Gazizov, Journal of Applied Spectroscopy, 77(3), 321-326 (2010)

11. A.V. Filippov, M.R. Artamonova, M.F. Rudakova, R.G. Gimatdinov, V.D. Skirda, Magnetic Resonance in Chemistry, 50(2), 114-118 (2012)

12. E.M. Alashkin, E.T. Kondratyeva, V.V. Kuzmin, K.R. Safullin, A.A. Stanislavovas, A.V. Savinkov, A.V. Klochkov, M.S. Tagirov, JEPT Letters, 107(2), 111-117 (2018)

13. V.V. Davydov, V.I. Dudkin, A.Yu. Karseev, Optical Memory \& Neural Networks (Information Optics), 23(3), 170 - 176 (2014)

14. V.V. Davydov, V.I. Dudkin, A.A. Petrov, N.S. Myazin, Technical Physics Letters, 42, 692-698 (2016)

15. D. Tarasova, A. Staritcyna, D. Nemova, K. Andreev, MATEC Web of Conferences, 53, 01007 (2016)

16. The National Petroleum Council 2007 after Craig, (Cunningham and Saigon, OECD/IEA, 2008)

17. V.E. Fortov, A.A. Makarov, Physics-Uspekhi, 52(12), 1249-1265 (2009)

18. I.I. Kryshev, L.A. Kurydina, I.I. Linge, Atomic Energy, 117(3), 159-163 (2014)

19. A.V. Moroz, V.V. Davydov, V.Yu. Rud, Y.V. Ryd, A.P. Glinushkin, Journal of Physics: Conference Series, 1135(1), 012060 (2018)

20. V.B. Fadeenko, V.V. Davydov, V.Yu. Rud, A.P. Glinushkin, Yu.V. Rud, V.Ch. Shpunt, Journal of Physics: Conference Series, 917(9), 092015 (2017)

21. I.A. Zharikov, R.V. Davydov, V.A. Lyapishev, V.Yu. Rud, Yu.V. Rud, A.P. Glynushkin, Journal of Physics: Conference Series, 917(5), 052011 (2017)

22. R.V. Davydov, V.Yu. Rud, Yu.V. Rud, E.I. Terukov, Journal of Physics: Conference Series, 1124(8), 081039 (2018)

23. V.V. Davydov, V.I. Dudkin, N.S. Myazin, Journal of Communications Technology and Electronics, 61(10), 1159-1165 (2016)

24. N.M. Grebenikova, K.J. Smirnov, V.V. Artemiev, V.V. Davydov, S.V. Kruzhalov, Journal of Physics: Conference Series, 1038(1), 012089 (2018)

25. V.V. Davydov, V.I. Dudkin, A.Yu. Karseev, Measurement Techniques, 58(3), 317-322 (2015)

26. V.V. Sergeev, M.R. Petrichenko, D.V. Nemova, E.V. Kotov, D.S. Tarasova, A.V. Nefedova, A.B. Borodinecs, Magazine of Civil Engineering, 84(8), 67-74 (2018)

27. V. Maslak, N. Nasonkina, V. Sakhnoskaya, S. Antonenko, D. Nemova, Procedia Engineering, 117(1), 985-994 (2015)
28. V. Mushchanov, V. Sievka, A. Veshnevska, D. Nemova, Procedia Engineering, 117(1), 1018-1026 (2015)

29. R. Davydov, V. Antonov, D. Molodtsov, A. Trebukhin, Advances in Intelligent Systems and Computing, 692, 915-920 (2018)

30. R. Davydov, V. Antonov, D. Molodtsov, A. Cheremisin, V. Korablev, MATEC Web of Conference, 245, 15002 (2018)

31. R.V. Davydov, V.I. Antonov, D.V. Molodtsov, Journal of Physics: Conference Series, 1135(1), 012088 (2018)

32. R.V. Davydov, V.I. Antonov, A.V. Moroz, Proceedings of the 2018 IEEE International Conference on Electrical Engineering and Photonics, EExPolytech, 8564378, 236-239 (2018)

33. N.M. Grebenikova, N.S. Myazin, V.Yu. Rud, R.V. Davydov, Proceedings of the 2018 IEEE International Conference on Electrical Engineering and Photonics, EExPolytech, 8564409 295-297 (2018)

34. V.V. Davydov, V.I. Dudkin, A.Yu. Karseev, V.A. Vologdin, Journal of Applied Spectroscopy, 82(6), 1013-1019 (2016)

35. N.S. Myazin, S.E. Logunov, V.V. Davydov, V.Yu. Rud', N.M. Grebenikova, V.V. Yushkova, Journal of Physics: Conference Series, 929(1), 012064 (2017)

36. V.V. Davydov, S.V. Kruzhalov, N.M. Grebenikova, K.J. Smirnov, Measurement Techniques, 61(4), 365372 (2018)

37. A.S. Podstrigaev, R.V. Davydov, V.Yu. Rud', V.V. Davydov, Lecture Notes in Computer Science (including subseries Lecture Notes in Artificial Intelligence and Lecture Notes in Bioinformatics), 11118 LNCS 624-630 (2018)

38. N.M. Grebenikova, K.J. Smirnov, V.V. Davydov, V.Y. Rud, Journal of Physics: Conference Series, 1124(4), 041011 (2018)

39. T. Fejling, E. Torosyan, O. Tsukanova, O. Kalinina, IOP Conference Series: Materials Science and Engineering, 497(1), 012027 (2019)

40. V. Vilken, O. Kalinina, S. Barykin, E. Zolotova, IOP Conference Series: Materials Science and Engineering, 497(1), 012037 (2019)

41. O. Kalinina, E. Balchik, S. Barykin, MATEC Web of Conference, 239, 04021 (2018)

42. V. Vilken, O. Kalinina, A. Dubgorn, E35 Web of Conference, 33, 03012 (2018)

43. A. Bril, O. Kalinina, A. Levina, E35 Web of Conference, 33, 03004 (2018)

44. E.V. Rykin, A.V. Moroz, K.J. Smirnov, V.V. Davydov, V.V. Yushkova, MATEC Web of Conference, 245, 12002 (2018)

45. M. Petrichenko, N. Vatin, D. Nemova, N. Kharkov, A. Staritcyna, Applied Mechanics and Materials, 627, 297-303 (2014) 
46. V.A. Grachev, V.A. Lobkovsky, Bioscie.

Biotechnol. Res. Asia, 12(1), 253-261 (2015) 